\title{
Variability of currents in front of the Venice Lagoon, Northern Adriatic Sea
}

\author{
S. Cosoli ${ }^{1}$, M. Gačić ${ }^{1}$, and A. Mazzoldi ${ }^{2}$ \\ ${ }^{1}$ Istituto Nazionale di Oceanografia e di Geofisica Sperimentale - OGS, Sgonico (Trieste), Italy \\ ${ }^{2}$ Istituto di Scienze Marine, Consiglio Nazionale delle Ricerche - ISMAR-CNR, Castello 1364/A, Venice, Italy \\ Received: 5 October 2007 - Revised: 18 February 2008 - Accepted: 22 February 2008 - Published: 13 May 2008
}

\begin{abstract}
Time scales and modes of variability of the flow in the water column in the Northern Adriatic Sea for late summer 2002 are described based on current record from a single bottom-mounted ADCP in the shallow-water area in front of the Venice Lagoon.
\end{abstract}

The time averaged flow was directed $277^{\circ} \mathrm{E}(\mathrm{CCW})$, roughly aligned with the coastline, with typical magnitudes in the range $4-6 \mathrm{~cm} / \mathrm{s}$ and a limited, not significant clockwise veering with depth. Tidal forcing was weak and mainly concentrated in the semidiurnal frequency band, with a barotropic (depth-independent) structure. On a diurnal time scale, tidal signal was biased by the sea-breeze regime and was characterized by a clockwise veering with depth according to the Ekman spiral.

A complex EOF analysis on the velocity profile time series extracted two dominant spatial modes of variability, which explained more than $90 \%$ of the total variance in the current field. More than $78 \%$ of the total variance was accounted for by the first EOF mode, with a barotropic structure that contained the low-frequency components and the barotropic tidal signal at semidiurnal and diurnal frequencies. The second mode had a baroclinic structure with a zero-crossing at mid-depth, which was related with the response of the water column to the high-frequency wind-driven diurnal sea breeze variability.

The response of low-passed non-tidal currents to local wind stress was fast and immediate, with negligible temporal lag up to mid-depth. Currents vectors were pointing to the right of wind stress, as expected from the surface Ekman veering, but with angles smaller than the expected ones. A time lag in the range 10 to $11 \mathrm{~h}$ was found below $8 \mathrm{~m}$ depth, with current vectors pointing to the left of wind stress and a counterclockwise veering towards the bottom. The delay was consistent with the frictional adjustment time scale describ-

Correspondence to: S. Cosoli

(scosoli@ogs.trieste.it) ing the dynamics of a frictionally dominated flow in shallow water, thus suggesting the importance of bottom friction on the motion over the entire water column.

Keywords. Oceanography: general (Continental shelf processes; Marginal and semi-closed seas) - Oceanography: physical (Air-sea interactions; Coriolis effects)

\section{Introduction}

The Adriatic Sea is a semi-enclosed, elongated basin bordered by the Italian coastline to the west and the Balkan regions to the East, and communicates with the Mediterranean Sea through the Otranto Strait at the South. The Northern Adriatic Sea is a relatively shallow basin in the northern sector, where the typical depth barely exceeds $25 \mathrm{~m}$. The general circulation of the Adriatic Sea is well-known from both numerical studies and observations (see Cushman-Roisin, 2001, for a detailed review), and is constituted by a cyclonic gyre with a northward flow along the Eastern side balanced by a southward return flow along the western boundary.

Like most of the continental shelves, buoyancy fluxes and the effects of both remote and local winds constitute the major forcing mechanisms of surface, mid-depth and bottom circulation patterns in the Adriatic Sea as a whole, and in its northern portion as well. For this area, in particular, numerical and experimental studies were carried out in order to describe sub-basin-scale features and relate them to the action of bora or sirocco winds (see for example the studies of Orlić et al., 1994; Bergamasco and Gačić, 1996, and references herein). More recent studies focused on the response of the Adriatic Sea to strong bora wind events, evidenced the presence of a complex, cyclonic and anticyclonic double-gyred pattern in the Northern Adriatic Sea (Kuzmić et al., 2006; Dorman et al., 2003), while an analysis of storm and nonstorm circulation of the basin provided a detailed description

Published by Copernicus Publications on behalf of the European Geosciences Union. 


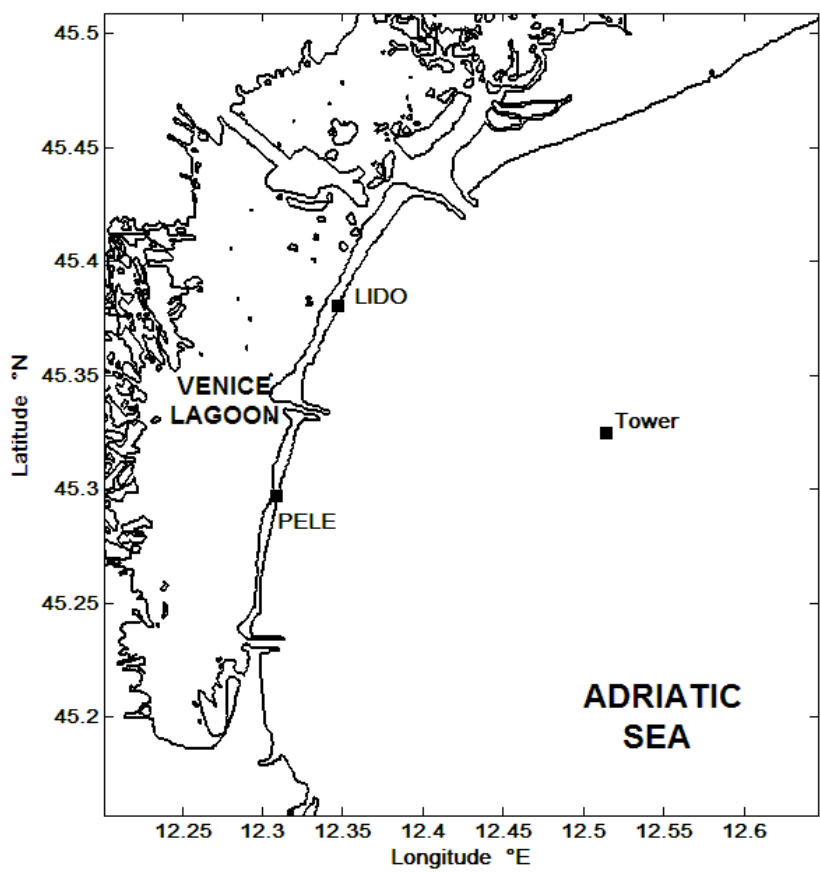

Fig. 1. Study area. Squares denote the locations of two radar stations (Kovačević et al., 2004) and the location of the oceanographic Tower where the bottom-mounted ADCP was located.

of the seasonal average transport in the Adriatic Sea (Book et al., 2005, 2007).

Most of these studies were focused on the transient response to short duration bora bursts, and did not take into consideration the effects of highly-variable wind regimes. The purpose of the present work is to extend the analysis of the response of near-surface currents to highly-variable winds, study its structure along the water column and assess the response time-scales, based on subsurface current records from a single bottom-mounted acoustic current-meter deployed in the shallow-water area in the Venice Gulf area. From a physical point of view, the limited depth of the investigated area means that the Ekman boundary layers potentially interact, with a partial or total overlap. In other words, this implies that two opposing phenomena may occur, the direct transfer of momentum from surface to bottom, while the bottom stresses tend to remove energy from the flow itself. A similar approach was applied in the inner continental shelf of the Mid Atlantic Bight, where the Delaware coastal current system was interpreted as linear superposition of wind-driven and buoyancy forced motions (Munchow and Garvine, 1993). More recently, a time scale was introduced in order to describe the temporal response of the water column to wind forcing in shallow-water shelf areas (Whitney and Garvine, 2005).

The analyzed data set data spans a 40-day long period from September to October 2002, when the local wind field was characterized by a significant presence of diurnal sea-breezes and the weather-frequency band (periodicities of few days) had limited contribution. In this season of the year the water column is often still stratified as for temperature and salinity, but the limited availability of in-situ data did not allow for a full assessment of the stratification contribution.

The work is organized as follows. Section 2 is dedicated to a description of the data set and the analysis technique, with emphasis on the complex Empirical Orthogonal Function (cEOF) analysis, while Sect. 3 provides a basic description of the data set. Following sections quantify the contribution of tides and their vertical structure, together with the spatial modes of variability of the water column and their typical time scales. The next section describes the response of the non-tidal currents to wind stress forcing and its propagation along the water column. Finally, the last section provides a summary together with the interpretation of the analysis results.

\section{Data and methods}

Subsurface ADCP current measurements near the Oceanographic Tower "Acqua Alta" (location $45^{\circ} 18.885^{\prime} \mathrm{N}$, $12^{\circ} 30.499^{\prime}$ E; Fig. 1) for the investigated period (SeptemberOctober 2002) were obtained from a $1200 \mathrm{kHz}$ bottommounted ADCP, deployed at $17 \mathrm{~m}$ depth in upward-looking configuration. These data were collected as part of a joint project between the US Naval Research Lab together with the NATO Undersea Research Center. A set of ADCP's were deployed in the Adriatic Sea for the period September 2002 to June 2003 (Book et al., 2007), as a joint effort to study the circulation of the Adriatic Sea over a wide range of time scales and forcing scenarios. The ADCP at the Tower was originally programmed to measure currents with $35 \mathrm{~cm}$ bin length, $40 \mathrm{~cm}$ blanking, and burst sampling every $2 \mathrm{~s}$ for $16 \mathrm{~min}$. Quality control procedures performed on the subsurface current records at each level excluded velocity data with estimated errors greater than $5 \mathrm{~cm} / \mathrm{s}$, as well as velocity data where more than $40 \%$ of the ping had bad data in two or more beams. Bins near the sea surface were excluded because of potential contamination from the surface echo. A magnetic variation correction of $1.56^{\circ}$ East of North was applied to data. A more detailed description of the quality control procedures adopted can be found in Book et al. (2007).

Time series of wind speed and direction originated from an anemometer located at $15-\mathrm{m}$ height on top of the tower (Fig. 1). Raw data consisted of five-minute averages of wind speed and direction, from which hourly time series were derived according to true vector averaging techniques, as recommended by NOAA-NDBC (National Ocean and Atmosphere Administration, National Data Buoy Center). Wind data were converted to the standard $10-\mathrm{m}$ height reference level prior to averaging following a logarithmic profile. Time series of wind stress were obtained following Large and Pond 
(1981) as $\tau=C_{d} W|W|$, with $C_{d}$ as a wind-speed dependent drag coefficient.

A least-squares tidal analysis (LSHA) technique was applied to ADCP data, in order to extract the astronomical contribution to current variance. The same technique was applied to wind stress vector in attempt to determine the presence of periodicities at diurnal frequency in the local forcing.

Tidal analyses were conducted using a standard, MATLAB-based package (Pawlowicz et al., 2002), derived from a FORTRAN code (Foreman, 1996), and ellipse parameters (semi-major and minor axes; inclination; phase angle) together with their $95 \%$ confidence levels were estimated for each component for every level along the vertical axis. A smaller subset of 7 harmonics, limiting the frequency range into the semidiurnal and diurnal tidal band but adequate to describe tidal variability in the Adriatic Sea (see Cushman-Roisin et al., 2001, for a review), was used for separating the tidal and non tidal contributions to current variance.

A rotary spectral analysis technique was applied in order to determine the variance distribution over frequencies and detect the typical time scales of the current variations. Coherently to classical one-sided spectrum of real-valued time series (Jenkins and Watts, 1969), two-sided rotary spectra for vector time series are defined as the Fourier transform of the cross-covariance function $R_{W_{j} W_{k}}(\tau)=\left\langle\boldsymbol{w}_{j}^{*}(\tau) \boldsymbol{w}_{k}(t+\tau)\right\rangle$, $(j, k=1,2),(-\infty<\tau<\infty)$. In terms of the Fourier amplitude spectra, the spectrum is given by:

$S_{W_{j} W_{k}}(\omega)=\left\langle\boldsymbol{W}_{j}^{*}(\omega) \boldsymbol{W}_{k}(\omega)\right\rangle$

where $\boldsymbol{w}_{j}, \boldsymbol{w}_{k}$ are two complex-valued representation for the vector time series and $\boldsymbol{W}_{j}, \boldsymbol{W}_{k}$ the corresponding Fourier representation, the asterisk $(*)$ is the complex conjugate operator, and \langle\rangle denotes the ensemble-average operator.

A complex correlation coefficient (Kundu, 1976) was used to estimate the correlation between vector time series together with the mean angular offset or veering between the two vectors. The complex correlation coefficient is defined as the normalized inner product of two vector time series:

$R=\rho \exp (i \alpha)=\frac{\left\langle\boldsymbol{w}_{1}^{*}(t) \boldsymbol{w}_{2}(t)\right\rangle}{\left\langle\boldsymbol{w}_{1}^{*}\left(t \boldsymbol{w}_{1}(t)\right\rangle\left\langle\boldsymbol{w}_{2}^{*}(t) \boldsymbol{w}_{2}(t)\right\rangle\right.}$

with $\rho$ being the magnitude of the correlation and $\alpha$ the average angular displacement of the second vector measured counterclockwise from the first one. The complex correlation coefficient is easily extended to a complex correlation function with the introduction of a time lag $\tau$ :

$R(\tau)=\frac{\left\langle\boldsymbol{w}_{1}^{*}(t) \boldsymbol{w}_{2}(t+\tau)\right\rangle}{\left\langle\boldsymbol{w}_{1}^{*}(t) \boldsymbol{w}_{1}(t)\right\rangle\left\langle\boldsymbol{w}_{2}^{*}(t) \boldsymbol{w}_{2}(t+\tau)\right\rangle}$

In order to identify the dominant vertical modes of variability of subsurface currents, an Empirical Orthogonal Function (EOF) analysis was performed on the time series of current profiles, and results were complemented with both rotary spectral analysis and LSHA so to determine their frequency content and typical time scales, and relate them to the local forcing.

The EOF analysis, also known as Karhunen-Loeve expansion (Kaihatu et al., 1998; North et al., 1982) is a statistical method that identifies preferred structures in the data set, summarizes the dominant properties (dominant spacetime patterns), and represents data in terms of orthogonal functions-or statistical modes- which are independent in space and uncorrelated in time with one another (Bjornsson and Venegas, 1997; Venegas, 2001). Due to the vector nature of the data field, the complex time series approach was used, and the complex EOF patterns that best represent the complex scalar field $U(x, t)$ in a mean-square sense (Kaihatu et al., 1998) were derived.

The independent EOF patterns were determined by solving the eigenvalue problem for the spatial covariance matrix of the simultaneous data from different locations (Davis, 1976). The solution of the eigenvalue problem for the covariance matrix, $\mathbf{R E}=\mathbf{E} \Lambda$, yields real-valued eigenvalues $\lambda_{i i}$ and complex eigenvectors associated with each eigenvalue. As for the real-valued EOF analysis, real eigenvalues represent the fraction of total variance accounted for by each eigenvector. For the $k$ th mode, the percent variance explained is given by:

$\operatorname{var}_{k}=\frac{\lambda_{k}}{\sum_{k} \lambda_{k}} \cdot 100$

where $\sum_{k} \lambda_{k}$ is the trace of the covariance matrix.

Errors in the estimate of the sample EOFs arise because experimental time series have finite duration and data are usually sampled over an irregularly spaced discrete grid. First-order error estimates for eigenvalues and eigenvectors were computed following North's rule-of-thumb (North et al., 1982) on the basis of the degree of separation between two consecutive eigenvalues $\left(\lambda_{j}, \lambda_{k}\right.$, respectively):

$\Delta \lambda_{k}=\sqrt{\frac{2}{N^{*}} \lambda_{k}}$

The typical errors between two consecutive eigenvectors $\left(\boldsymbol{E}_{j}, \boldsymbol{E}_{k}\right.$, respectively) was then computed as:

$\Delta \boldsymbol{E}_{k} \simeq \frac{\Delta \lambda_{k}}{\lambda_{j}-\lambda_{k}} \boldsymbol{E}_{j}$

with $\lambda_{j}$ eigenvalue and eigenvector closest to $\lambda_{k}, \boldsymbol{E}_{k}$.

Interpretation of the errors reads as follow: if the sampling error for a particular eigenvalue $\lambda_{i}$ is comparable with or larger than the spacing between $\lambda_{i}$ itself and a neighboring eigenvalue, then sampling errors in the EOF associated with $\lambda_{i}$ will be comparable to the size of the neighboring EOF. According to North's rule-of-thumb, then, if a group of eigenvalues lie within one-two times the each other's associated errors, they form an effectively degenerate multiplet: 
Data return for ADCP bins

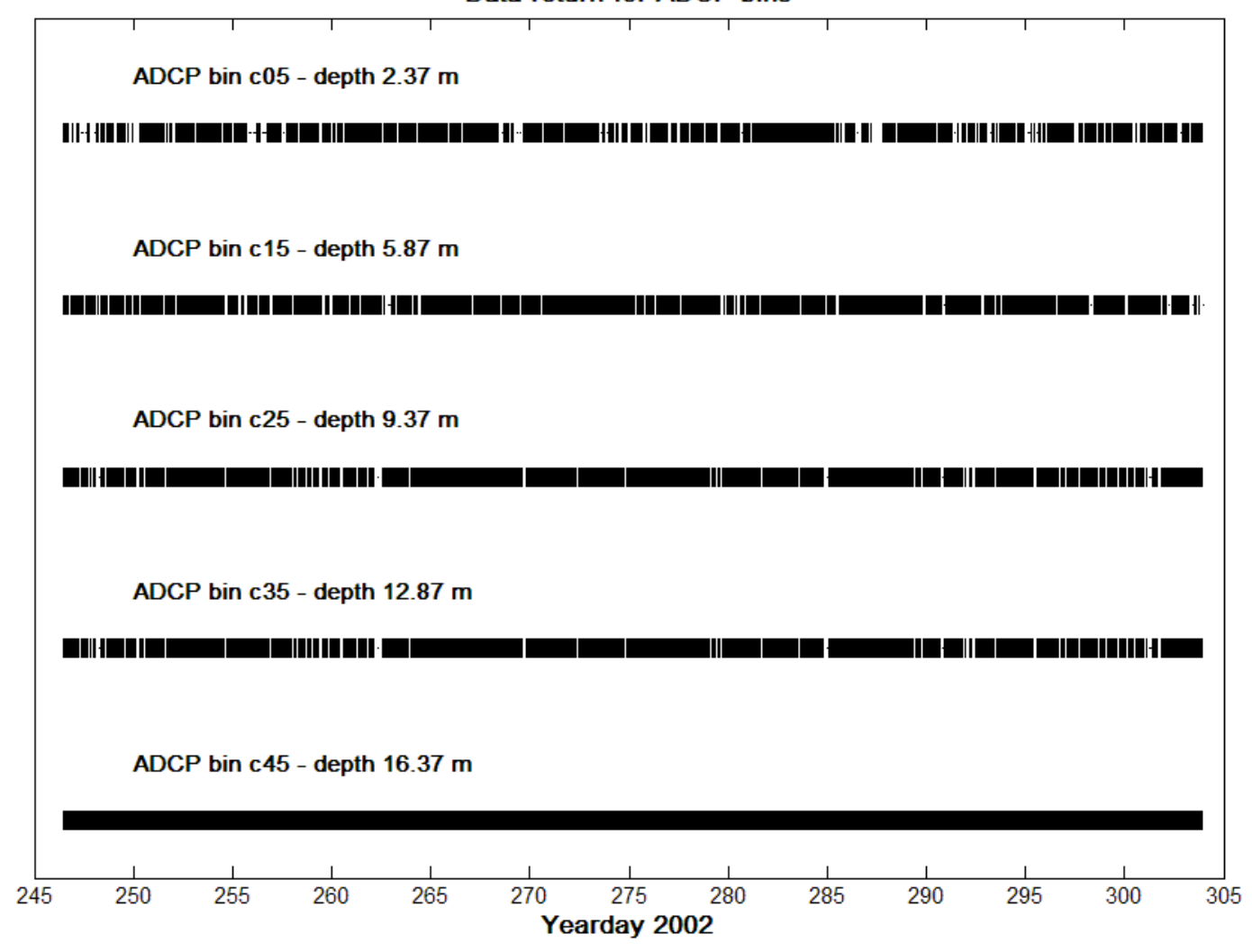

Fig. 2. Data availability for the period September-October 2002, for five ADCP bins named C05, C15, C25, C35, C45, located, respectively, at the nominal depth of $2.37 \mathrm{~m}, 5.87 \mathrm{~m}, 9.37 \mathrm{~m}, 12.87 \mathrm{~m}, 16.37 \mathrm{~m}$.

sample eigenvectors are not separate, and do not correspond to distinct modes of variability but constitute a random mixture of the true eigenvectors.

\section{Exploratory data analysis}

Data availability for the investigated period are depicted in Fig. 2 for five levels along the water column (C05, C15, C25, $\mathrm{C} 35$, C45), located, respectively, at the nominal depth of $2.37 \mathrm{~m}, 5.87 \mathrm{~m}, 9.37 \mathrm{~m}, 12.87 \mathrm{~m}, 16.37 \mathrm{~m}$. Time series were almost complete at all levels along the water column since more than $87 \%$ of the total data were available in the upper bin ( $177 \mathrm{~h}$ of missing data), and more than $95 \%$ of the data were on average available along the water column. For the level closest to surface, gaps larger than 4 consecutive hours seldom occurred, and the largest gap (12 h) occurred on 15 October 07:00 to 18:00.

Time series of velocities at three different levels, together with wind speed, are presented in Fig. 3. The plot evidences a fairly good agreement between currents (lower panels) and wind (uppermost panel). Strong winds blowing from the NE sectors (i.e. the "bora" wind) have a significant effect over the entire water column (days 263 to 268; days 280 to 285), since the entire water column was constrained in a $\mathrm{NE}$ to SW direction that followed the bora wind principal axis. On the other hand, current reversals between surface and bottom also occurred during the investigated period, mostly under weak wind conditions when the wind showed only daily variability (days 270 to 280 ; days 288 to 290).

Basic statistical properties (maxima, minima, mean, median, standard deviations, root-mean-square values) for the hourly time series of the $U$ (East-West), $V$ (North-South) components of currents, expressed in a Cartesian coordinate frame of reference, are summarized in Table 1. Five levels are considered, spanning the levels from $2.37 \mathrm{~m}$ to $16.37 \mathrm{~m}$ depths. As expected, the largest values, ranges, standard deviations and RMS values were found at the level closest to surface. For the $U$ component, the absolute value of their amplitudes did not exceed $40 \mathrm{~cm} / \mathrm{s}$ in both the East and the West directions, while for the $V$ component maximum values did not exceed $25 \mathrm{~cm} / \mathrm{s}$ in the North direction and maximum values in the South direction were below $45 \mathrm{~cm} / \mathrm{s}$. Mean and median values were both low and negative, decreased in amplitude from surface to bottom together with the standard deviations and root-mean-square values, with a veering to the right of surface values at bottom. The resulting time averaged 
Table 1. Basic statistical properties (maxima and minima, mean and median, standard deviation and root-mean-squares) of subsurface currents for the period September to October 2002. Table 1a refers to the U component, while Table $1 \mathrm{~b}$ contain statistics for the V component. Units are $\mathrm{cm} / \mathrm{s}$.

\begin{tabular}{|c|c|c|c|c|c|c|c|}
\hline \multicolumn{2}{|c|}{ (a) U component } & \multirow[b]{2}{*}{$\operatorname{Max}(\mathrm{cm} / \mathrm{s})$} & \multirow[b]{2}{*}{$\operatorname{Min}(\mathrm{cm} / \mathrm{s})$} & \multirow[b]{2}{*}{ Mean $(\mathrm{cm} / \mathrm{s})$} & \multirow[b]{2}{*}{ Median (cm/s) } & \multirow[b]{2}{*}{ Std $(\mathrm{cm} / \mathrm{s})$} & \multirow[b]{2}{*}{$\mathrm{RMS}(\mathrm{cm} / \mathrm{s})$} \\
\hline Bin & Depth (m) & & & & & & \\
\hline $\mathrm{C} 05$ & 2.37 & 39.3 & -37.5 & -6.3 & -6.8 & 10.6 & 12.4 \\
\hline C15 & 5.87 & 19.6 & -33 & -5.3 & -4.7 & 8.5 & 10 \\
\hline $\mathrm{C} 25$ & 9.37 & 14.2 & -29.3 & -4.5 & -4 & 7.5 & 8.7 \\
\hline $\mathrm{C} 35$ & 12.87 & 18.7 & -25 & -3.6 & -3 & 7.2 & 8.1 \\
\hline $\mathrm{C} 45$ & 16.37 & 15 & -22 & -2 & -2.3 & 5.4 & 5.8 \\
\hline
\end{tabular}

(b) $\mathrm{V}$ component

\begin{tabular}{cccccccc}
\hline Bin & Depth $(\mathrm{m})$ & Max $(\mathrm{cm} / \mathrm{s})$ & Min $(\mathrm{cm} / \mathrm{s})$ & Mean $(\mathrm{cm} / \mathrm{s})$ & Median $(\mathrm{cm} / \mathrm{s})$ & Std $(\mathrm{cm} / \mathrm{s})$ & RMS $(\mathrm{cm} / \mathrm{s})$ \\
\hline C05 & 2.37 & 17.7 & -43 & -6.6 & -6.2 & 9 & 11.2 \\
C15 & 5.87 & 15.8 & -36 & -5.4 & -5.1 & 7.8 & 9.5 \\
C25 & 9.37 & 23.8 & -29.4 & -3.8 & -4.3 & 8 & 8.8 \\
C35 & 12.87 & 19.4 & -26.8 & -3.4 & -3.1 & 8 & 8.7 \\
C45 & 16.37 & 17 & -24 & -3 & -3.2 & 6.8 & 7.5 \\
\hline
\end{tabular}

flow had thus a southwestward component accordingly to the mean cyclonic circulation pattern reported in Kovačević et al. (2004) for surface current derived from HF radars, and evidenced in Book et al. (2007) for the mean vertically averaged currents under storm and non storm conditions. Typical values at surface reached $-6.3 \mathrm{~cm} / \mathrm{s}$ and $-6.6 \mathrm{~cm} / \mathrm{s}$ for the $U, V$ components, respectively, were lower than $6 \mathrm{~cm} / \mathrm{s}$ at mid-depth, and lower than $4 \mathrm{~cm} / \mathrm{s}$ at bottom.

The rotary spectra presented in Fig. 4 summarize the main spectral properties of near-surface and bottom currents, together with wind variance distribution. The dominant tidal constituents (namely, the semidiurnal and the diurnal tides) and the local inertial frequency are evidenced in the frequency axis of current spectra. The tidal diurnal and the local inertial frequency are evidenced in the wind rotary stress frequency axis. For both the cyclonic and anti-cyclonic spectra (upper and lower panels, respectively), the variance content was larger at surface then bottom levels. In the lowfrequency band (periods longer than $40 \mathrm{~h}$ ), energy at surface and bottom was larger in the cyclonic than the anti-cyclonic spectrum. On the other hand, current variance appeared to be larger in the anti-cyclonic spectrum than the cyclonic portion for the frequency band spanning $17 \mathrm{~h}$ to $26 \mathrm{~h}$. In the same frequency band, peaks in both the cyclonic and anticyclonic wind stress could be detected, suggesting an influence of wind over currents at these frequencies, as revealed by LSHA of wind stress data (Table 2a).

On a semidiurnal frequency, a prominent peak was found in both counter-rotating portions of the spectrum, with no reduction in amplitude over depth occurring in the cyclonic spectrum (upper panel) and on the contrary present in the anti-cyclonic spectrum (lower panel). No clear peaks could be detected in the high-frequency tails of the spectra.

\section{Contribution of tides}

According to harmonic analysis results, summarized in Table $2 b$ to $d$ for the dominant constituents, tidal forcing was weak, since astronomical tides explained $15 \%$ to $18 \%$ of the total current variance. The largest contribution was associated with the semidiurnal and diurnal tidal band, at the M2 and S2 (periods $12.42 \mathrm{~h}$ and $12 \mathrm{~h}$ ) and $\mathrm{K} 1$ (period 23.93 h) harmonics, respectively. The remaining variance was distributed amongst high frequency (inertial motions, seiches, jets or small scale eddies) and low frequency forcing with periods of the order of days.

The vertical structure of the dominant semidiurnal tidal constituents (M2, S2) showed a barotropic structure with negligible reduction in amplitude over depth (Fig. 5). Ellipse major axes for the M2 tide ranged from $4 \mathrm{~cm} / \mathrm{s}(1 \mathrm{~cm} / \mathrm{s}$ error) at surface, to $3 \mathrm{~cm} / \mathrm{s}(0.6 \mathrm{~cm} / \mathrm{s}$ error $)$ at bottom. The positive values for the minor axes, with typical magnitudes of order $2 \mathrm{~cm} / \mathrm{s}$, suggested a counterclockwise rotation of the current vector along the ellipse. Inclination of the major axes showed a slight clockwise veering with depth, but ellipses tend to cluster around the average angle of $123^{\circ} \mathrm{E}$ (standard deviation $5^{\circ}$ ), and differences in ellipse orientation were anyhow within the estimated errors. For the S2 constituent, a trend in ellipse inclination with depth similar to that found for the M2 tide was not clearly detected, since a more erratic spread around the average value of $125^{\circ} \mathrm{E}$ (standard deviation $3^{\circ}$ ) was observed. A slight increase with depth in phase angle for the M2 tide was observed, meaning a moderate time lag between surface and bottom, which again was not present in the $\mathrm{S} 2$ tide.

A different pattern characterized the diurnal tidal constituent K1, since this constituent showed a strong shear in 

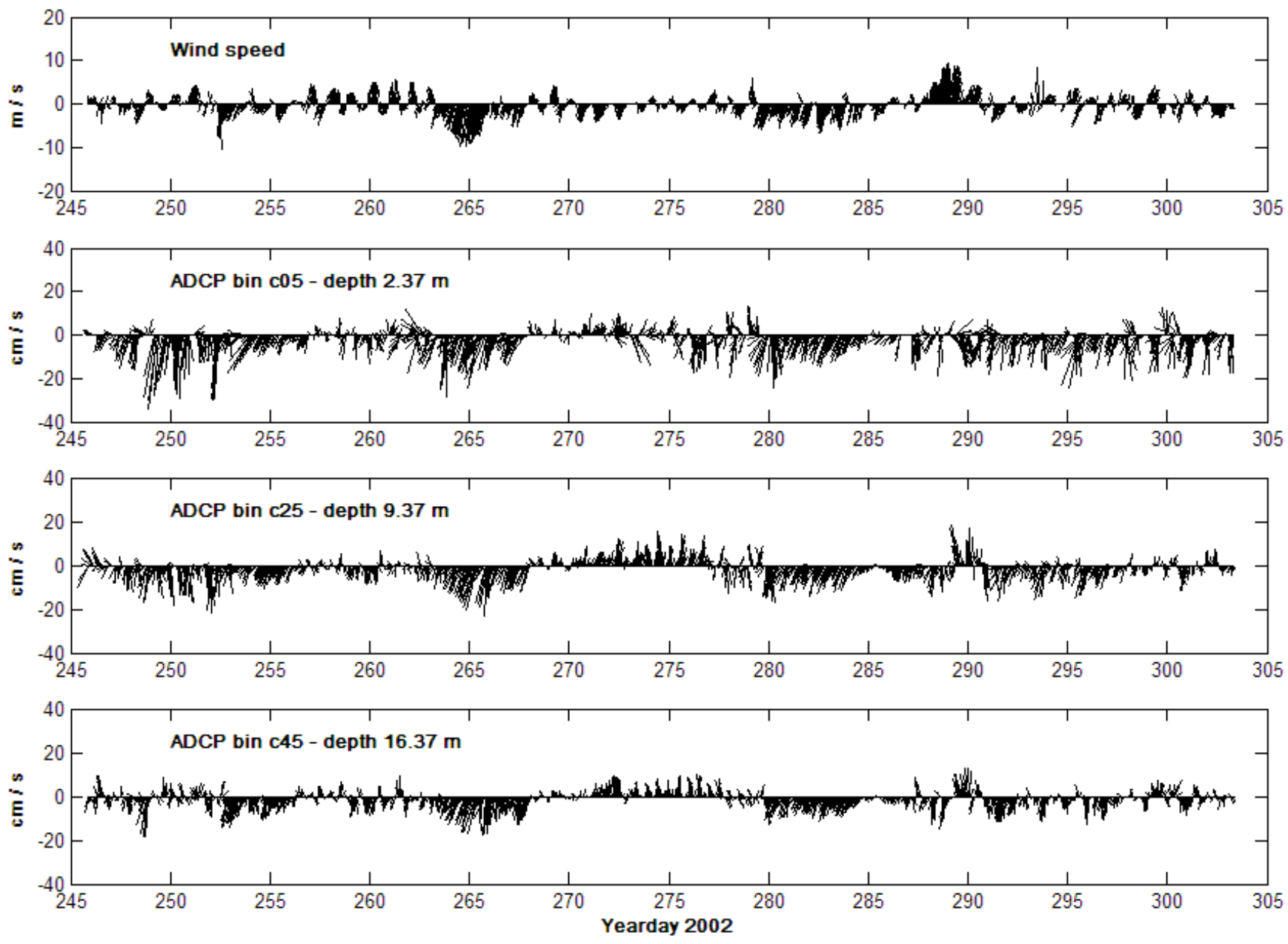

Fig. 3. Time series of wind speed at the oceanographic tower (upper panel) and currents at $2.37 \mathrm{~m}, 9.37 \mathrm{~m}$ and $16.37 \mathrm{~m}$ depths. Units are $\mathrm{m} / \mathrm{s}$ for wind speed, $\mathrm{cm} / \mathrm{s}$ for currents.

amplitude and a clockwise veering in ellipse inclination with depth (Fig. 6). The angular offset between the levels closest to surface and bottom was $75^{\circ}$, but reached $105^{\circ}$ at middepth. As already evidenced from the rotary spectra of surface and bottom current records, energy content at this frequency band significantly reduced over depth, due to the superposition of the effect of wind forcing on a diurnal time scale (sea-breeze and diurnal tide), which was responsible for most of the differences between shore-based HF radarderived surface currents and near-surface current measurements (Cosoli et al., 2005).

A strong signal at the long term, low frequency tidal band was also detected from the harmonic analyses, in the frequency band associated with the Msf tide (period $~ 14$ days). Amplitudes of the corresponding major axes ranged from $8 \mathrm{~cm} / \mathrm{s}$ (error $3 \mathrm{~cm} / \mathrm{s}$ ) at surface, with a mean inclination of $30^{\circ} \mathrm{E}$ (error $30^{\circ}$ ), to $5 \mathrm{~cm} / \mathrm{s}$ (error $2 \mathrm{~cm} / \mathrm{s}$ ) and an inclination of $66^{\circ} \mathrm{E}$ (error $21^{\circ}$ ) at bottom. A counterclockwise veering in ellipse inclination with depth was found, resulting in a $30^{\circ}$ offset in direction between surface and bottom, without significant phase lag along the water column.

\section{EOF analysis of current profiles}

Due to the weak contribution of tides to the total current variance, and due also to the contamination of diurnal wind on the K1 harmonic, the complex EOF analysis (cEOF) was applied to the original time series of current profiles without detiding. The temporal mean was subtracted from current time series at each depth prior to cEOF analysis. Results of the analysis are presented in Fig. 7 in terms of the sample eigenvalue spectrum (upper panel) and the cumulative variance spectrum (lower panel), while Table 3 synthesizes the percent variance explained by the first five modes together with the cumulative variance percentage. Table 4 contains a summary of the LSHA performed on the expansion coefficients for the 4 dominant EOF modes. As for the analysis of 

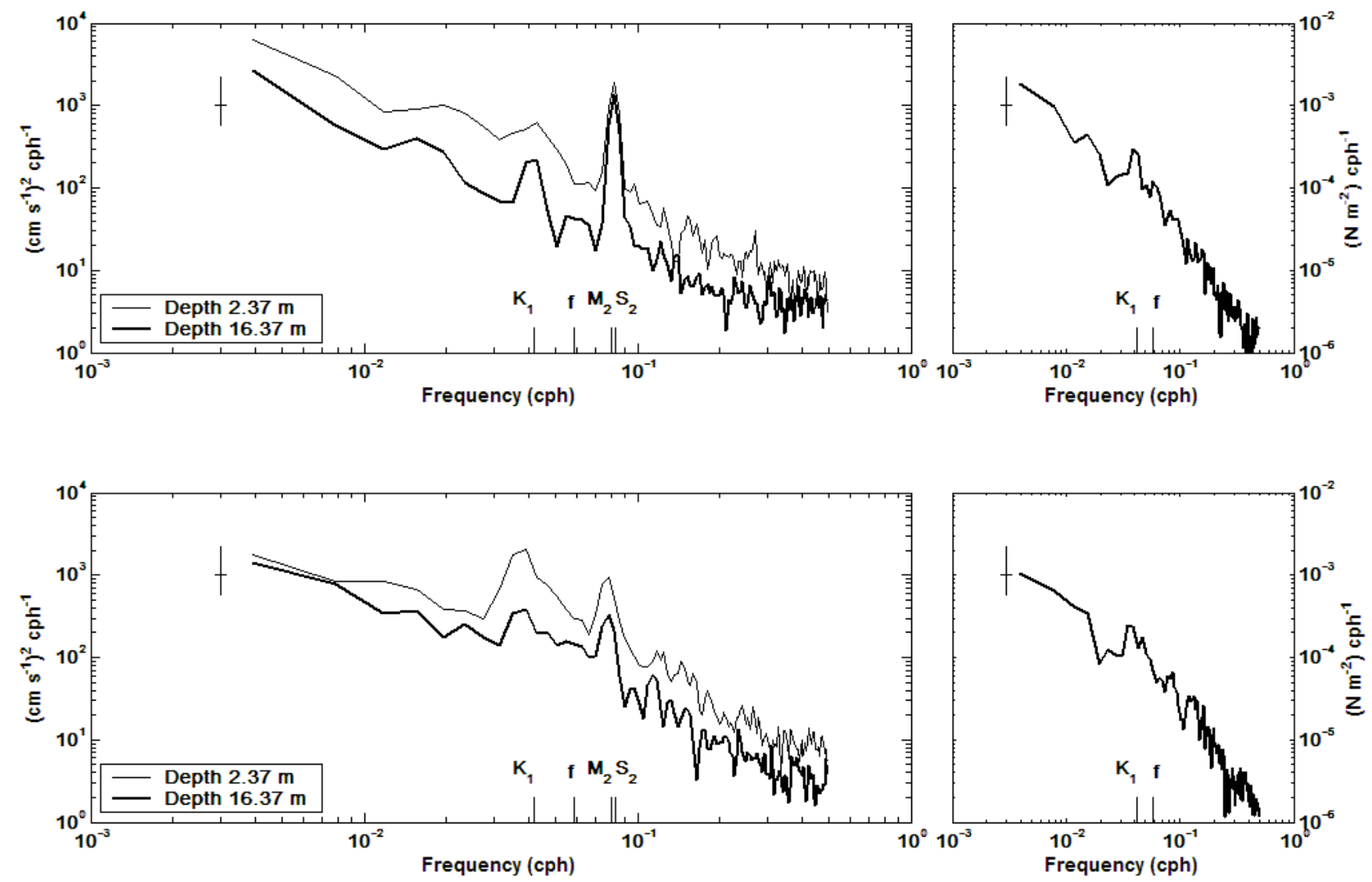

Fig. 4. Cyclonic and anticyclonic spectra for near-surface (thin line), bottom currents (bold line) and wind stress variance. Vertical error bars denote the $95 \%$ confidence level. Upper panel refers to the cyclonic spectrum (counterclockwise rotations), while the lower panel refers to the anticyclonic spectrum (clockwise rotations). The dominant tidal constituents are evidenced in the frequency axis.

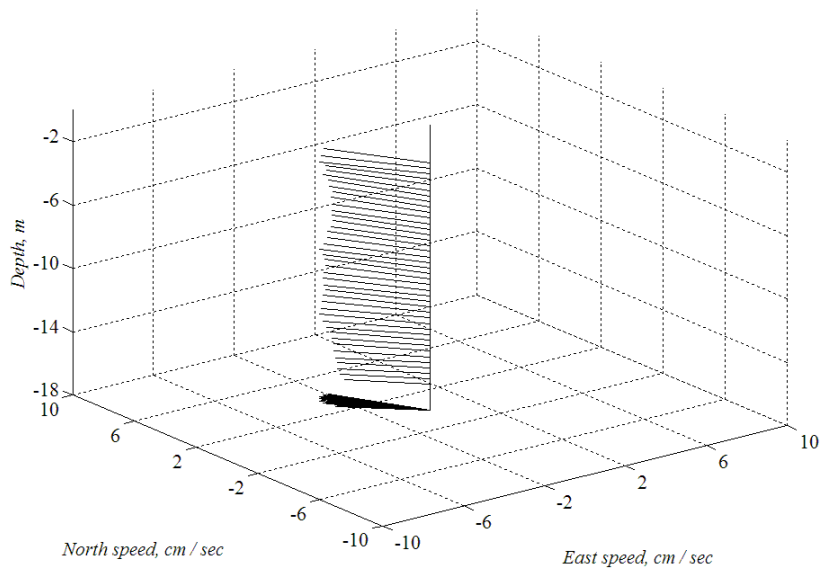

Fig. 5. Vertical structure of tidal ellipse amplitudes for the semidiurnal (M2) frequency. Units are $\mathrm{cm} / \mathrm{s}$ for the east, north speed (x, y) axes, and $\mathrm{m}$ for the depth-axis (z-axis).

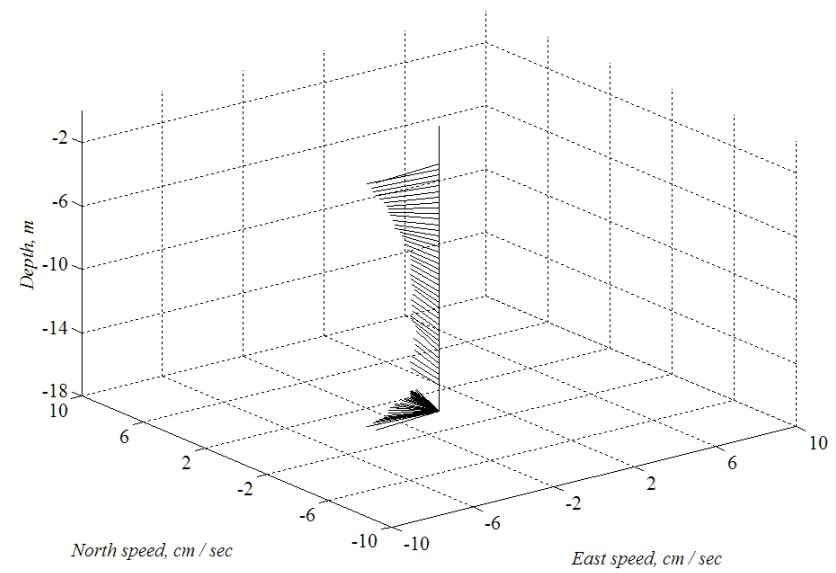

Fig. 6. Vertical structure of tidal ellipse amplitudes for the diurnal (K1) frequency. Units are $\mathrm{cm} / \mathrm{s}$ for the east, north speed (x, y) axes, and $\mathrm{m}$ for the depth-axis (z-axis). 
Table 2. Tidal ellipses parameters (major and minor axis, inclination and phase) together with 95\% confidence levels (Emaj, Emin, Einc, Epha) for the dominant (Msf, K1, M2, S2) tidal constituents. Panel (a) refers to wind stress vector, while panels (b), (c) and (d) refer to surface $(2.37 \mathrm{~m})$, mid-depth $(9.37 \mathrm{~m})$ and bottom $(16.37 \mathrm{~m})$ currents. Ellipse inclinations are measured counterclockwise from the E.

\begin{tabular}{|c|c|c|c|c|c|c|c|c|c|}
\hline $\begin{array}{l}\text { (a) } \\
\text { Tide }\end{array}$ & $\begin{array}{l}\text { Frequency } \\
\quad(\mathrm{cph})\end{array}$ & $\begin{array}{c}\text { Maj }(10 \times) \\
\left(\mathrm{N} / \mathrm{m}^{2}\right)\end{array}$ & $\begin{array}{c}\text { Emaj }(10 \times) \\
\left(\mathrm{N} / \mathrm{m}^{2}\right)\end{array}$ & $\begin{array}{c}\operatorname{Min}(10 \times) \\
\left(\mathrm{N} / \mathrm{m}^{2}\right)\end{array}$ & $\begin{array}{c}\operatorname{Emin}(10 \times) \\
\left(\mathrm{N} / \mathrm{m}^{2}\right)\end{array}$ & $\begin{array}{l}\text { Inc } \\
\left({ }^{\circ} \mathrm{E}\right)\end{array}$ & $\begin{array}{l}\text { Einc } \\
\left({ }^{\circ} \mathrm{E}\right)\end{array}$ & Pha & Epha \\
\hline MSF & 0.0028219 & 4.1 & 2.6 & -0.2 & 2.3 & 41 & 41 & 266 & 40 \\
\hline K1 & 0.0417807 & 1.6 & 0.6 & -0.1 & 0.8 & 60 & 27 & 190 & 24 \\
\hline M2 & 0.0805114 & 0.3 & 0.3 & 0.1 & 0.3 & 5 & 114 & 23 & 117 \\
\hline $\mathrm{S} 2$ & 0.0833333 & 0.4 & 0.4 & -0.06 & 0.4 & 148 & 71 & 225 & 80 \\
\hline \multicolumn{10}{|l|}{ (b) } \\
\hline Tide & $\begin{array}{l}\text { Frequency } \\
\quad(\mathrm{cph})\end{array}$ & $\begin{array}{c}\text { Maj } \\
(\mathrm{cm} / \mathrm{s})\end{array}$ & $\begin{array}{l}\text { Emaj } \\
(\mathrm{cm} / \mathrm{s})\end{array}$ & $\begin{array}{l}\text { Min } \\
(\mathrm{cm} / \mathrm{s})\end{array}$ & $\begin{array}{l}\text { Emin } \\
(\mathrm{cm} / \mathrm{s})\end{array}$ & $\begin{array}{l}\text { Inc } \\
\left({ }^{\circ} \mathrm{E}\right)\end{array}$ & $\begin{array}{l}\text { Einc } \\
\left({ }^{\circ} \mathrm{E}\right)\end{array}$ & Pha & Epha \\
\hline MSF & 0.0028219 & 8 & 3.3 & -1.3 & 3.4 & 30 & 30 & 254 & 27 \\
\hline $\mathrm{K} 1$ & 0.0417807 & 3.3 & 1.4 & -0.5 & 1.2 & 5 & 19 & 192 & 28 \\
\hline M2 & 0.0805114 & 4.3 & 0.9 & 1.3 & 1 & 121 & 16 & 161 & 17 \\
\hline $\mathrm{S} 2$ & 0.0833333 & 3.2 & 0.9 & 1 & 0.95 & 120 & 22 & 163 & 22 \\
\hline \multicolumn{10}{|l|}{ (c) } \\
\hline Tide & $\begin{array}{l}\text { Frequency } \\
\quad(\mathrm{cph})\end{array}$ & $\begin{array}{c}\text { Maj } \\
(\mathrm{cm} / \mathrm{s})\end{array}$ & $\begin{array}{l}\text { Emaj } \\
(\mathrm{cm} / \mathrm{s})\end{array}$ & $\begin{array}{l}\operatorname{Min} \\
(\mathrm{cm} / \mathrm{s})\end{array}$ & $\begin{array}{l}\text { Emin } \\
(\mathrm{cm} / \mathrm{s})\end{array}$ & $\begin{array}{l}\text { Inc } \\
\left({ }^{\circ} \mathrm{E}\right)\end{array}$ & $\begin{array}{l}\text { Einc } \\
\left({ }^{\circ} \mathrm{E}\right)\end{array}$ & Pha & Epha \\
\hline MSF & 0.0028219 & 7.3 & 2.8 & -0.1 & 2 & 51 & 20 & 257 & 22 \\
\hline $\mathrm{K} 1$ & 0.0417807 & 2.1 & 0.0 & 0.1 & 1.8 & 83 & 28 & 194 & 21 \\
\hline M2 & 0.0805114 & 4.1 & 0.6 & 1.7 & 0.5 & 120 & 11 & 172 & 11 \\
\hline $\mathrm{S} 2$ & 0.0833333 & 3.2 & 0.6 & 1.2 & 0.5 & 122 & 12 & 177 & 12 \\
\hline \multicolumn{10}{|l|}{ (d) } \\
\hline Tide & $\begin{array}{l}\text { Frequency } \\
\quad(\mathrm{cph})\end{array}$ & $\begin{array}{c}\text { Maj } \\
(\mathrm{cm} / \mathrm{s})\end{array}$ & $\begin{array}{l}\text { Emaj } \\
(\mathrm{cm} / \mathrm{s})\end{array}$ & $\begin{array}{l}\operatorname{Min} \\
(\mathrm{cm} / \mathrm{s})\end{array}$ & $\begin{array}{l}\text { Emin } \\
(\mathrm{cm} / \mathrm{s})\end{array}$ & $\begin{array}{l}\text { Inc } \\
\left({ }^{\circ} \mathrm{E}\right)\end{array}$ & $\begin{array}{l}\text { Einc } \\
\left({ }^{\circ} \mathrm{E}\right)\end{array}$ & Pha & Epha \\
\hline MSF & 0.0028219 & 4.5 & 1.8 & 0.1 & 1.8 & 66 & 21 & 261 & 24 \\
\hline $\mathrm{K} 1$ & 0.0417807 & 2.3 & 0.7 & -0.4 & 0.7 & 80 & 17 & 301 & 17 \\
\hline M2 & 0.0805114 & 3.1 & 0.5 & 1.3 & 0.6 & 133 & 13 & 179 & 13 \\
\hline $\mathrm{S} 2$ & 0.0833333 & 2.5 & 0.5 & 1.2 & 0.6 & 119 & 18 & 162 & 16 \\
\hline
\end{tabular}

Table 3. Eigenvalues associated with the first 5 EOF modes, the fraction of variance retained by each mode and the cumulative variance. An asterisk denotes the statistically significant EOF modes.

\begin{tabular}{cccc}
\hline $\begin{array}{c}\text { Mode } \\
\text { Number }\end{array}$ & Eigenvalue & $\begin{array}{c}\text { Explained } \\
\text { Variance }\end{array}$ & $\begin{array}{c}\text { Cumulative } \\
\text { Variance }\end{array}$ \\
\hline (*)Mode-1 & $3.56 \mathrm{E}+03$ & 70.63 & 70.63 \\
$(*)$ Mode-2 & $1.04 \mathrm{E}+03$ & 20.62 & 91.25 \\
$(*)$ Mode-3 & $1.94 \mathrm{E}+02$ & 3.85 & 95.11 \\
$(*)$ Mode-4 & $7.96 \mathrm{E}+01$ & 1.58 & 96.68 \\
Mode-5 & $4.15 \mathrm{E}+01$ & 0.82 & 97.51 \\
\hline
\end{tabular}

subsurface currents, tidal ellipse parameters (major and minor axis, inclination and phase angle) for the dominant harmonics were estimated and complemented with their $95 \%$ confidence levels (emaj, emin, einc, epha).
Two modes were required to reach the $90 \%$ of total variance, a reasonable threshold for truncating an EOF expansion (Venegas, 2001). EOF mode-1 accounted for more than 70\% of the total variance, while about $20 \%$ of the total variance is explained by EOF mode- 2 . Mode- 3 and mode- 4 together accounted for about $5 \%$ of the total variance, while no significant contribution was provided by higher-order modes.

According to error estimates of sample eigenvalues of finite-length records, the first two modes were well resolved, since first-order estimates for the error bars at 68\%, 95\% and $99 \%$ confidence levels were far from overlapping to each other. In a similar way mode- 2 and mode- 3 were resolved, since error bars for $68 \%$ to $99 \%$ confidence levels did not overlap. However, mode-3 was not resolved from either mode -4 and higher order modes, because the small differences existing between these eigenvalues render the solutions for higher order modes ambiguous. 

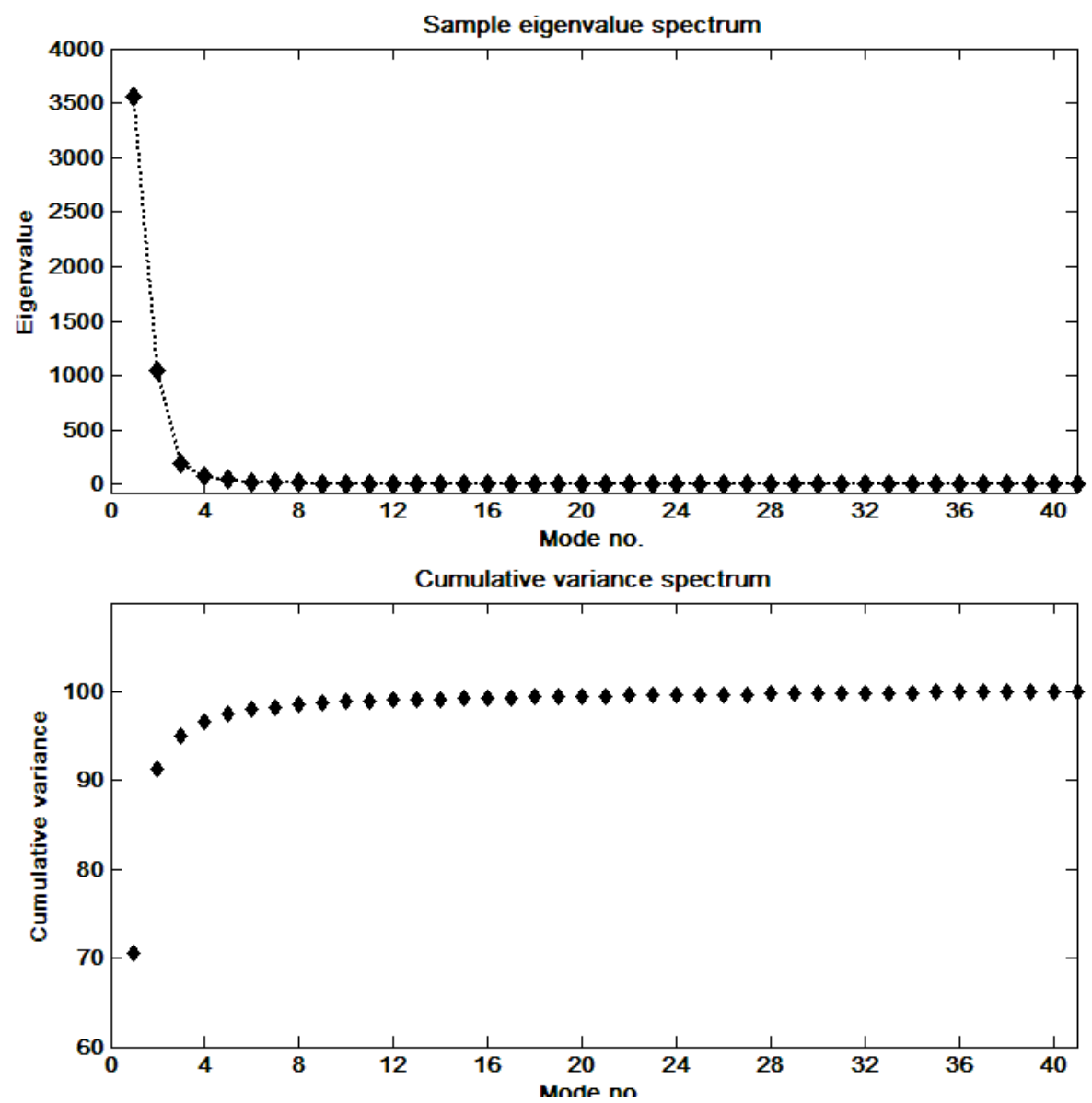

Fig. 7. Sample eigenvalue spectrum (upper panel), and cumulative variance spectrum (lower panel) from the cEOF analysis of current profiles for the period September-October 2002.

Mode-1 showed a depth uniform vertical structure with small reductions in amplitude towards the surface and the bottom together with a clockwise veering with depth, related to effects of a bottom-friction dominated bottom boundary layer (Munchow and Chant, 2000) (Figs. 8, 9a). It can be interpreted as the barotropic mode of the system. Time series of temporal amplitude and phase angle, depicted in Fig. 9d, e, showed high frequency forcing, superimposed to lowfrequency components with duration from 3 to about 10 days. Two-sided rotary spectra of temporal amplitudes for mode-1, obtained as a composite of 256-h long subsets, evidenced a sharp peak at the semidiurnal frequencies in both the anticyclonic spectrum, and in the cyclonic spectrum (Fig. 9c), and was related to the semidiurnal and low frequency tidal band (Table 4a).

EOF mode- 2 accounted for more than $20 \%$ of the total variance, and was characterized by a baroclinic-like structure with one zero-crossing at $8 \mathrm{~m}$ depth and phase opposition between near-surface and the bottom layers (Figs. 10a, b; 11). Amplitudes of modal coefficients (Fig. 10e) were generally smaller than those for mode- 1 , while the time series of tem-

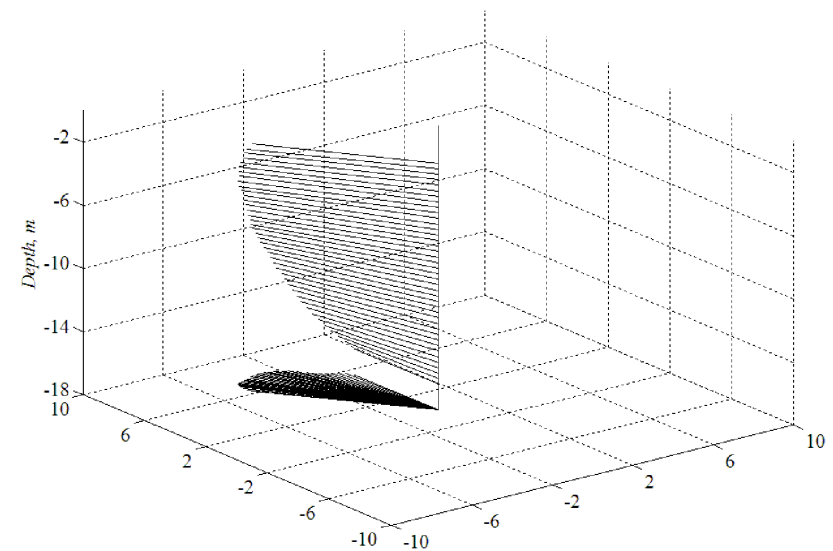

Fig. 8. 3-D representation of the vertical structure of EOF mode-1 of the current profiles for the investigated period. Amplitudes are drawn at the ADCP vertical resolution, namely every $35 \mathrm{~cm}$.

poral phase revealed the prevalence of short-term, periodic or nearly periodic components (periods $22-25 \mathrm{~h}$ ) superimposed to (occasional) longer-duration (1 to 3 days) events 

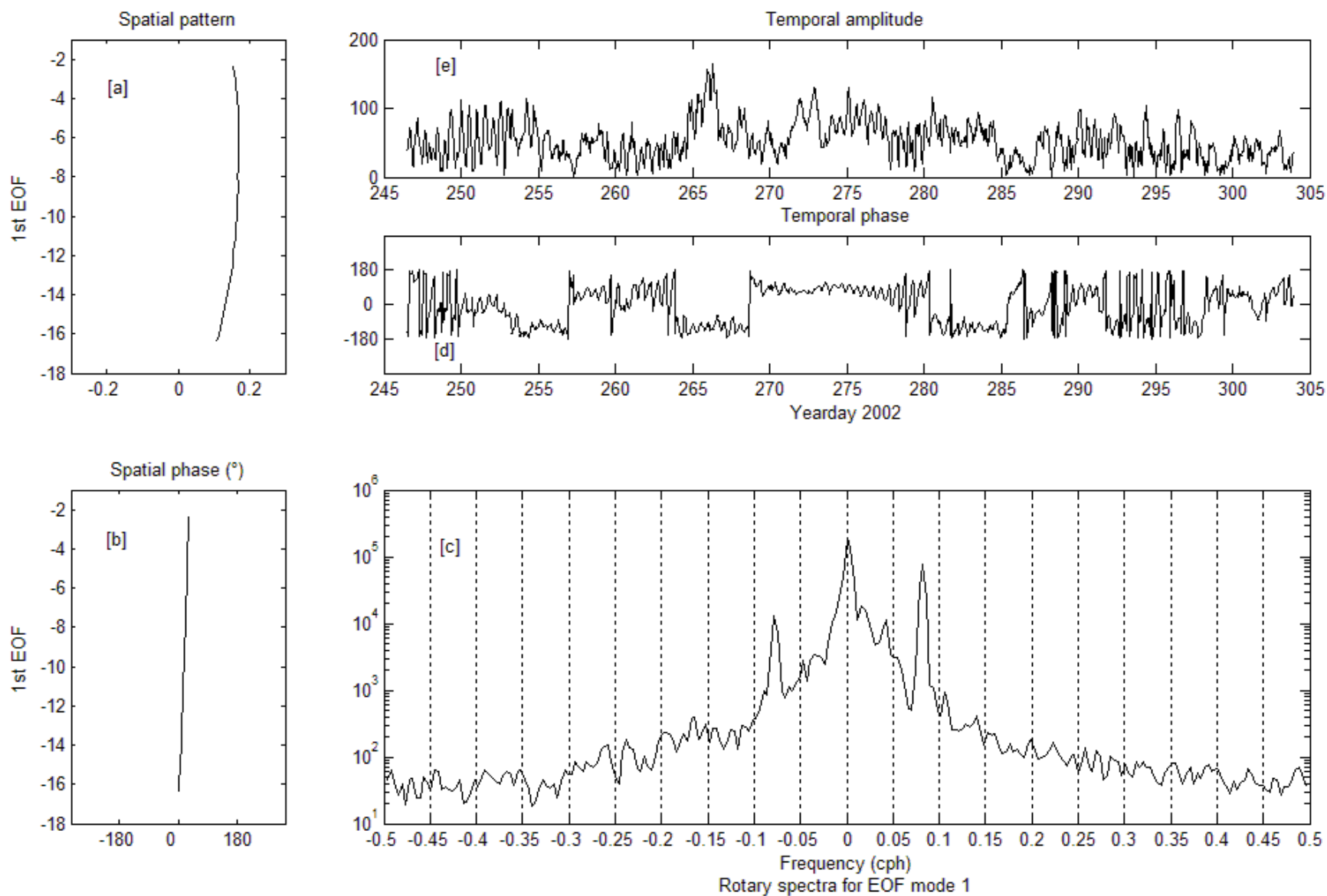

Fig. 9. Interpretation of the first EOF mode derived from the analysis of ADCP time series of current profiles at the Oceanographic Tower for the period September-October 2002. In a counterclockwise sense from the upper-left corner, the panels read as follows:

(a) Spatial pattern showing the vertical structure for the first EOF mode along the water column; (b) Spatial phase showing information on phase lag form top to bottom of the water column. The spatial pattern is non-dimensional, while units for the spatial phase are degrees. Units for the vertical axis are $\mathrm{m}$. (c) Two-sided rotary spectrum for the expansion coefficients associated to the EOF modes, partitioning variance into dominant time scales. Units for the y-axis are $(\mathrm{cm} / \mathrm{s})^{2} / \mathrm{cph}$. (d), (e) Time series of temporal phase angle and expansion coefficients, showing the time evolution of the spatial pattern over time. Units for the spatial phase angle are degrees; units for the expansion coefficients are $\mathrm{cm} / \mathrm{s}$.

(Fig. 10d). Most of the variance for this mode is distributed within the diurnal band in the anticyclonic spectrum, while the low frequency and the semidiurnal bands had 1 order of magnitude less energy than mode-1 (Fig. 10c). A sharp, welldefined peak at the semidiurnal signal was still present in the cyclonic spectrum. For this mode, tidal analysis (Table $4 \mathrm{~b}$ ) evidenced the presence of significant contribution at the diurnal frequency.

The remaining modes (mode- 3 and mode-4) showed a strong variability both in space and in time. The two modes had, respectively, 2 and 3 zero-crossings, with $180^{\circ}$ phase jumps and strong vertical shears over the water column. A weak signal at the diurnal frequency was extracted by LSHA of mode- 3 coefficient time series, but was significantly lower than mode-2. The diurnal signal was also extracted from mode- 4 , but was 4 to 5 times smaller than mode- 1 and mode-
2. For both modes, contribution at the semidiurnal frequencies was negligible, being 1 to 2 orders of magnitudes lower than other modes. No energy was detected in the low frequency band for both modes.

\section{Contribution of winds}

In order to determine the response of the signal in current field to wind forcing, its propagation along the water column and to identify time scales for current response to wind forcing, a lagged vector cross-correlation approach was adopted, in which wind stress vector was related to the currents along the water column. Due to the potential contamination of tides in the diurnal frequency band, the analysis was carried out on the low-passed portion of the subsurface currents and wind 

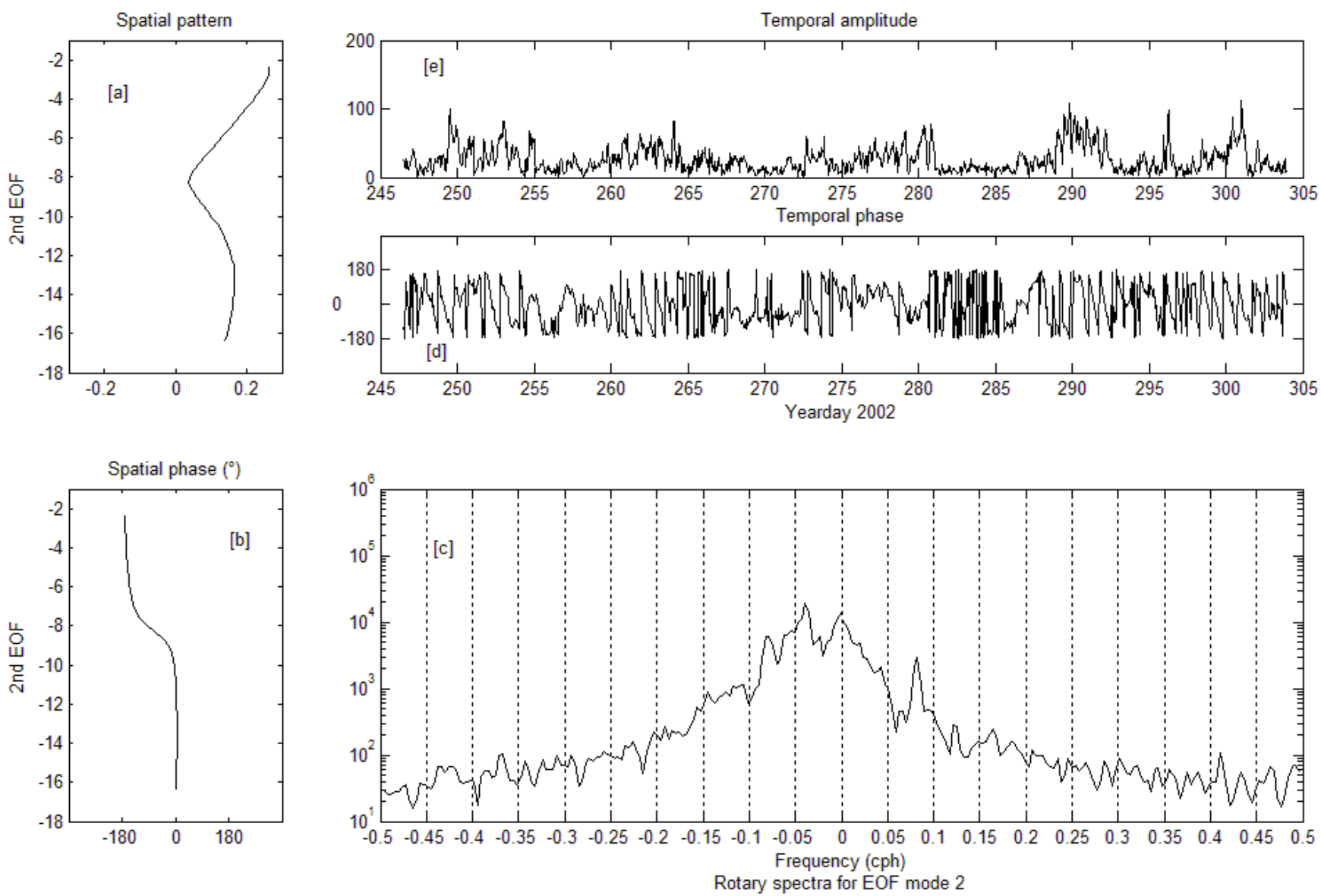

Fig. 10. Interpretation of the second EOF mode derived from the analysis of ADCP time series of current profiles at the Oceanographic Tower for the period September-October 2002. In a clockwise sense from the upper-left corner, the panels read as follows: (a) Spatial pattern showing the vertical structure for the first EOF mode along the water column; (b) Spatial phase showing information on phase lag form top to bottom of the water column. The spatial pattern is non-dimensional, while units for the spatial phase are degrees. Units for the vertical axis are m. (c) Two-sided rotary spectrum for the expansion coefficients associated to the EOF modes, partitioning variance into dominant time scales. Units for the y-axis are $(\mathrm{cm} / \mathrm{s})^{2} / \mathrm{cph}$. (d), (e) Time series of temporal phase angle and expansion coefficients, showing the time evolution of the spatial pattern over time. Units for the spatial phase angle are degrees; units for the expansion coefficients are $\mathrm{cm} / \mathrm{s}$.

stress. As for the EOF analysis, current time series at every level were de-meaned prior to low-pass and prior performing the correlation analysis.

Table 5 summarizes the results of the correlation analyses for nine levels along the water column. The columns in the table provide, for each ADCP level considered, the corresponding depth, the module of the correlation coefficient and veering angle at zero lag, the lag at which correlation is maximized, together with the maximum lag correlation magnitude and veering. The two panels in Fig. 12 provide a plot of the correlation magnitude (upper panel) and the veering angle (lower panel) over lag for the vector cross-correlation function $(\mathrm{CCF})$ between wind stress and ADCP data for two levels (subsurface and bottom). The $2.37 \mathrm{~m}$ level (solid line) was considered representative of the upper portion of the water column, a surface layer that quickly adjusts to wind variations, while the dash-dotted line represents the response of the bottom layer, having almost constant lag of 10-11 h with respect to upper layer. As evidenced by the CCF for nearsurface currents (Fig. 12), the response to wind stress at surface was almost immediate since correlation was maximized at $1-\mathrm{h}$ lag with a $24^{\circ}$ veering to the right of the wind stress vector. The lag of maximum correlation with wind stress vector constantly increased along the water column reaching 8-h at 8-m depth, with currents to the right of wind stress vector. At the lag of maximum correlation, the amplitude was generally larger than the corresponding zero-lag values, but no significant variation in the veering angle was observed.

Below the 8-m level, maximum correlation was found with a $10-11 \mathrm{~h}$ delay, and the veering angles were negative, meaning that currents were pointing to the left of the wind stress vector.

In order to test the significance of the correlation values, confidence levels for the vector correlation were obtained 
Table 4. Tidal ellipses parameters (major and minor axis, ellipse inclination and phase), together with their 95\% errors (Emaj, Emin, Epha, Einc) of the expansion coefficients of the 4 leading EOF modes, for the low frequency, diurnal and semidiurnal tidal bands.

\begin{tabular}{|c|c|c|c|c|c|c|c|c|c|}
\hline $\begin{array}{c}\text { (a) EOF mode- } 1 \\
\text { Tide }\end{array}$ & $\begin{array}{l}\text { Frequency } \\
\quad(\mathrm{cph})\end{array}$ & $\begin{array}{c}\text { Maj } \\
(\mathrm{cm} / \mathrm{s})\end{array}$ & $\begin{array}{l}\text { Emaj } \\
(\mathrm{cm} / \mathrm{s})\end{array}$ & $\begin{array}{c}\operatorname{Min} \\
(\mathrm{cm} / \mathrm{s})\end{array}$ & $\begin{array}{l}\text { Emin } \\
(\mathrm{cm} / \mathrm{s})\end{array}$ & $\begin{array}{l}\text { Inc } \\
\left({ }^{\circ} \mathrm{E}\right)\end{array}$ & $\begin{array}{l}\text { Einc } \\
\left({ }^{\circ} \mathrm{E}\right)\end{array}$ & Pha & Epha \\
\hline MSF & 0.0028219 & 44 & 19.1 & -2.8 & 9.7 & 70 & 11 & 255 & 24 \\
\hline $\mathrm{K} 1$ & 0.0417807 & 12.5 & 3.1 & 6 & 3.7 & 100 & 24 & 294 & 20 \\
\hline M2 & 0.0805114 & 24.7 & 2 & 9.7 & 2 & 144 & 6 & 173 & 6 \\
\hline $\mathrm{S} 2$ & 0.0833333 & 16 & 1.9 & 7 & 2 & 148 & 10 & 179 & 9 \\
\hline \multicolumn{10}{|l|}{ (b) EOF mode-2 } \\
\hline Tide & $\begin{array}{l}\text { Frequency } \\
\quad(\mathrm{cph})\end{array}$ & $\begin{array}{c}\text { Maj } \\
(\mathrm{cm} / \mathrm{s})\end{array}$ & $\begin{array}{l}\text { Emaj } \\
(\mathrm{cm} / \mathrm{s})\end{array}$ & $\begin{array}{l}\operatorname{Min} \\
(\mathrm{cm} / \mathrm{s})\end{array}$ & $\begin{array}{l}\text { Emin } \\
(\mathrm{cm} / \mathrm{s})\end{array}$ & $\begin{array}{l}\text { Inc } \\
\left({ }^{\circ} \mathrm{E}\right)\end{array}$ & $\begin{array}{l}\text { Einc } \\
\left({ }^{\circ} \mathrm{E}\right)\end{array}$ & Pha & Epha \\
\hline MSF & 0.0028219 & 4 & 4.7 & -1.3 & 4.8 & 101 & 106 & 351 & 96 \\
\hline $\mathrm{K} 1$ & 0.0417807 & 10.8 & 3.8 & -6.4 & 3.6 & 38 & 37 & 336 & 38 \\
\hline M2 & 0.0805114 & 3.2 & 2.7 & 2.7 & 2.6 & 101 & 112 & 219 & 115 \\
\hline $\mathrm{S} 2$ & 0.0833333 & 2.5 & 2.5 & 1 & 2.5 & 84 & 81 & 190 & 99 \\
\hline \multicolumn{10}{|l|}{ (c) EOF mode-3 } \\
\hline Tide & $\begin{array}{l}\text { Frequency } \\
\quad(\mathrm{cph})\end{array}$ & $\begin{array}{c}\text { Maj } \\
(\mathrm{cm} / \mathrm{s})\end{array}$ & $\begin{array}{l}\text { Emaj } \\
(\mathrm{cm} / \mathrm{s})\end{array}$ & $\begin{array}{l}\operatorname{Min} \\
(\mathrm{cm} / \mathrm{s})\end{array}$ & $\begin{array}{l}\text { Emin } \\
(\mathrm{cm} / \mathrm{s})\end{array}$ & $\begin{array}{l}\text { Inc } \\
\left({ }^{\circ} \mathrm{E}\right)\end{array}$ & $\begin{array}{l}\text { Einc } \\
\left({ }^{\circ} \mathrm{E}\right)\end{array}$ & Pha & Epha \\
\hline MSF & 0.0028219 & 1.2 & 1.7 & 0.2 & 1.7 & 100 & 137 & 79 & 99 \\
\hline $\mathrm{K} 1$ & 0.0417807 & 2.8 & 1.8 & -0.4 & 1.5 & 150 & 37 & 49 & 42 \\
\hline M2 & 0.0805114 & 1.4 & 1.2 & 0.6 & 1.2 & 111 & 73 & 183 & 68 \\
\hline $\mathrm{S} 2$ & 0.0833333 & 1.2 & 1 & 0.2 & 1.1 & 92 & 82 & 161 & 67 \\
\hline \multicolumn{10}{|l|}{ (d) EOF mode-4 } \\
\hline Tide & $\begin{array}{l}\text { Frequency } \\
\quad(\mathrm{cph})\end{array}$ & $\begin{array}{c}\text { Maj } \\
(\mathrm{cm} / \mathrm{s})\end{array}$ & $\begin{array}{l}\text { Emaj } \\
(\mathrm{cm} / \mathrm{s})\end{array}$ & $\begin{array}{l}\operatorname{Min} \\
(\mathrm{cm} / \mathrm{s})\end{array}$ & $\begin{array}{l}\text { Emin } \\
(\mathrm{cm} / \mathrm{s})\end{array}$ & $\begin{array}{l}\text { Inc } \\
\left({ }^{\circ} \mathrm{E}\right)\end{array}$ & $\begin{array}{l}\text { Einc } \\
\left({ }^{\circ} \mathrm{E}\right)\end{array}$ & Pha & Epha \\
\hline MSF & 0.0028219 & 1 & 1.2 & 0.1 & 1 & 14 & 70 & 46 & 80 \\
\hline K1 & 0.0417807 & 2.1 & 1.1 & -1 & 1.2 & 34 & 54 & 173 & 54 \\
\hline M2 & 0.0805114 & 0.4 & 0.9 & -0.3 & 0.8 & 46 & 129 & 231 & 163 \\
\hline $\mathrm{S} 2$ & 0.0833333 & 0.7 & 0.8 & 0.2 & 0.9 & 145 & 83 & 334 & 98 \\
\hline
\end{tabular}

performing a bootstrap analysis on resampled time series of wind stress and currents at each depth. Vector correlation was then computed for each resampled time series along the water column. The procedure was performed 1000 times in order to obtain a distribution of simulated vector correlation coefficients, and the approximate $95 \%$ confidence intervals were estimated from the 2.5 th and 97.5 th percentiles. Results suggested that up to the $8 \mathrm{~m}$ depth the correlation values at maximum lag were not statistically different from the zero-lag values for delay up to $6-8 \mathrm{~h}$. On the other hand, the 11-h lag correlation found below 8-m level was statistically different from both the zero-lag correlation at this depth and the surface correlation at zero-lag.

\section{Summary and concluding remarks}

This paper presented the vertical modes of variability and the corresponding time scales for the motion of subsurface currents in the shallow water area in front of the Venice Lagoon, in the Northern Adriatic Sea area. Rather than addressing the response to strong bora winds, which occur as localized episodes in time during the year (as for instance in Kuzmić et al., 2007), or focusing on the storm or non-storm induced circulation (Book et al., 2007) for which the water column can be considered homogeneous, attention is focused on the stratified season (September to October 2002) when vertical density stratification is potentially still present and the wind regime is characterized by high variability on a diurnal time scale.

In this work, a detailed hydrographic analysis of the water column and the possible influences on the motion of the 
Table 5. Lagged vector correlation between wind stress and low-passed non tidal currents. Amplitude and angular offset of correlation at zero-lag are shown in 3rd and 4th columns, while columns 5th to 7th give the lag at which correlation is maximized, the amplitude of correlation and the angular displacement at the corresponding lag. First and second columns contain, respectively, the code and the depth of each ADCP cell.

\begin{tabular}{|c|c|c|c|c|c|c|}
\hline \multicolumn{7}{|c|}{ Correlation low-passed wind stress VS low-passed currents } \\
\hline & $\begin{array}{l}\text { Depth } \\
\text { (m) }\end{array}$ & $\begin{array}{l}\text { Zero-lag } \\
\text { correlation }\end{array}$ & $\begin{array}{c}\text { Zero-lag } \\
\text { veering angle } \\
\text { (degrees) }\end{array}$ & $\begin{array}{l}\text { Lag maximum } \\
\text { correlation } \\
\text { (hours) }\end{array}$ & $\begin{array}{c}\text { Maximum lag } \\
\text { correlation }\end{array}$ & $\begin{array}{c}\text { Maximum lag } \\
\text { veering angle } \\
\text { (degrees) }\end{array}$ \\
\hline $\mathrm{C} 05$ & -2.37 & 0.54 & 24 & 1 & 0.55 & 24 \\
\hline $\mathrm{C} 10$ & -4.12 & 0.53 & 26 & 3 & 0.54 & 26 \\
\hline $\mathrm{C} 15$ & -5.87 & 0.52 & 21 & 6 & 0.54 & 20 \\
\hline $\mathrm{C} 20$ & -7.62 & 0.50 & 13 & 8 & 0.54 & 11 \\
\hline $\mathrm{C} 25$ & -9.37 & 0.47 & 1 & 11 & 0.55 & 1 \\
\hline C30 & -11.12 & 0.47 & -8 & 11 & 0.55 & -4 \\
\hline $\mathrm{C} 35$ & -12.87 & 0.47 & -13 & 11 & 0.56 & -8 \\
\hline $\mathrm{C} 40$ & -14.62 & 0.47 & -17 & 11 & 0.55 & -12 \\
\hline C45 & -16.37 & 0.48 & -23 & 10 & 0.58 & -19 \\
\hline
\end{tabular}

water column was not performed, due to the limited availability of vertical profiles of temperature and salinity. In order to account for the presence and the role of vertical stratification, a number of CTD casts performed at the end of October 2002 in front of the Istrian peninsula were analyzed, calculating the Brunt-Vaisala frequency and the internal Rossby deformation radius. Field data evidenced the presence of a weak stratification, with a linear trend in the density profiles from surface to bottom in most of the stations, or a gentlysloping pycnocline between 20 to $30 \mathrm{~m}$ depths. The value for the Brunt-Vaisala frequency yielded an internal Rossby deformation radius of about $6 \mathrm{~km}$, suggesting that the location of the investigated point - about 8 miles distant from the coast) was outside the area influenced by boundary currents.

The time averaged flow for the investigated period was directed in a SW direction, with magnitudes not exceeding $7 \mathrm{~cm} / \mathrm{s}$ along the water column, and a limited veering from surface to bottom. A variety of processes and different time scales were found to contribute to the vertical current profile variability. Rotary spectra revealed peaks in the semidiurnal frequency band associated with the semidiurnal tidal constituents (M2, S2 harmonics), without significant reduction in amplitude over depth in the cyclonic spectrum, and with minor differences between surface and bottom levels in the anti-cyclonic spectrum. The diurnal frequency band, on the other hand, had larger variance in the anti-cyclonic spectrum than the cyclonic portion. In the low-frequency band, variance in the cyclonic spectrum was again larger than the counter-rotating spectrum.

The contribution of tides was weak and limited to the semidiurnal and diurnal harmonics (M2, S2 and K1 components, respectively). The semidiurnal tides showed a barotropic (depth-independent) vertical pattern with limited reduction in amplitude and negligible veering with depth. In

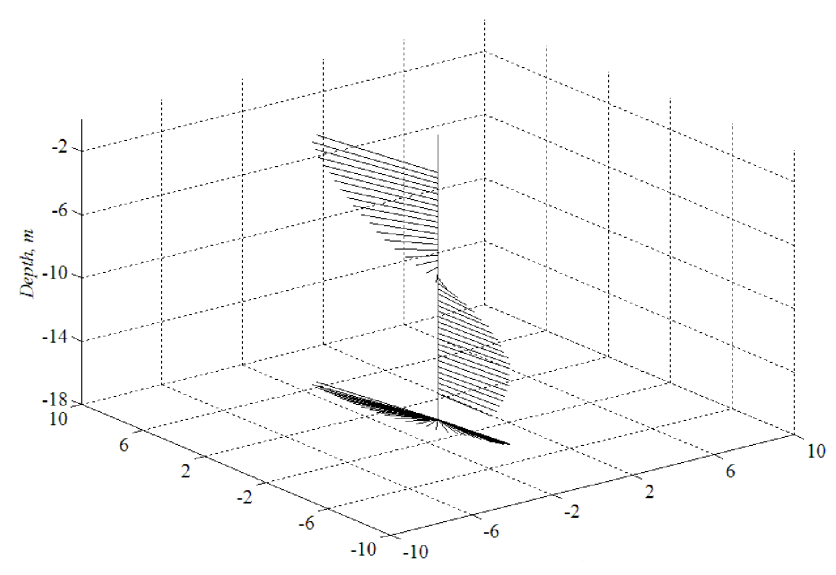

Fig. 11. 3-D representation of the vertical structure of EOF mode2. Amplitudes are drawn at the ADCP vertical resolution, namely every $35 \mathrm{~cm}$.

the diurnal frequency band, contamination from the diurnal sea breeze wind regime significantly biased results of the tidal analysis since the vertical pattern for the K1 harmonic at this frequency revealed a baroclinic structure, with significant clockwise veering along the water column. A similar phenomenon was described for moored current meter records offshore Oregon coast, where diurnal wind stress forcing related to diurnal sea-breeze regime was found to severely contaminate current variance at the K1 tidal diurnal frequency band (Rosenfeld, 1988).

Also, the harmonic analyses of our wind stress data evidenced that wind stress had a component in the diurnal frequency band at the $\mathrm{K} 1$ tidal frequency, with ellipse inclination oriented $55^{\circ}$ to the left of near-surface ADCP K1 ellipse, in agreement with the Ekman veering. 

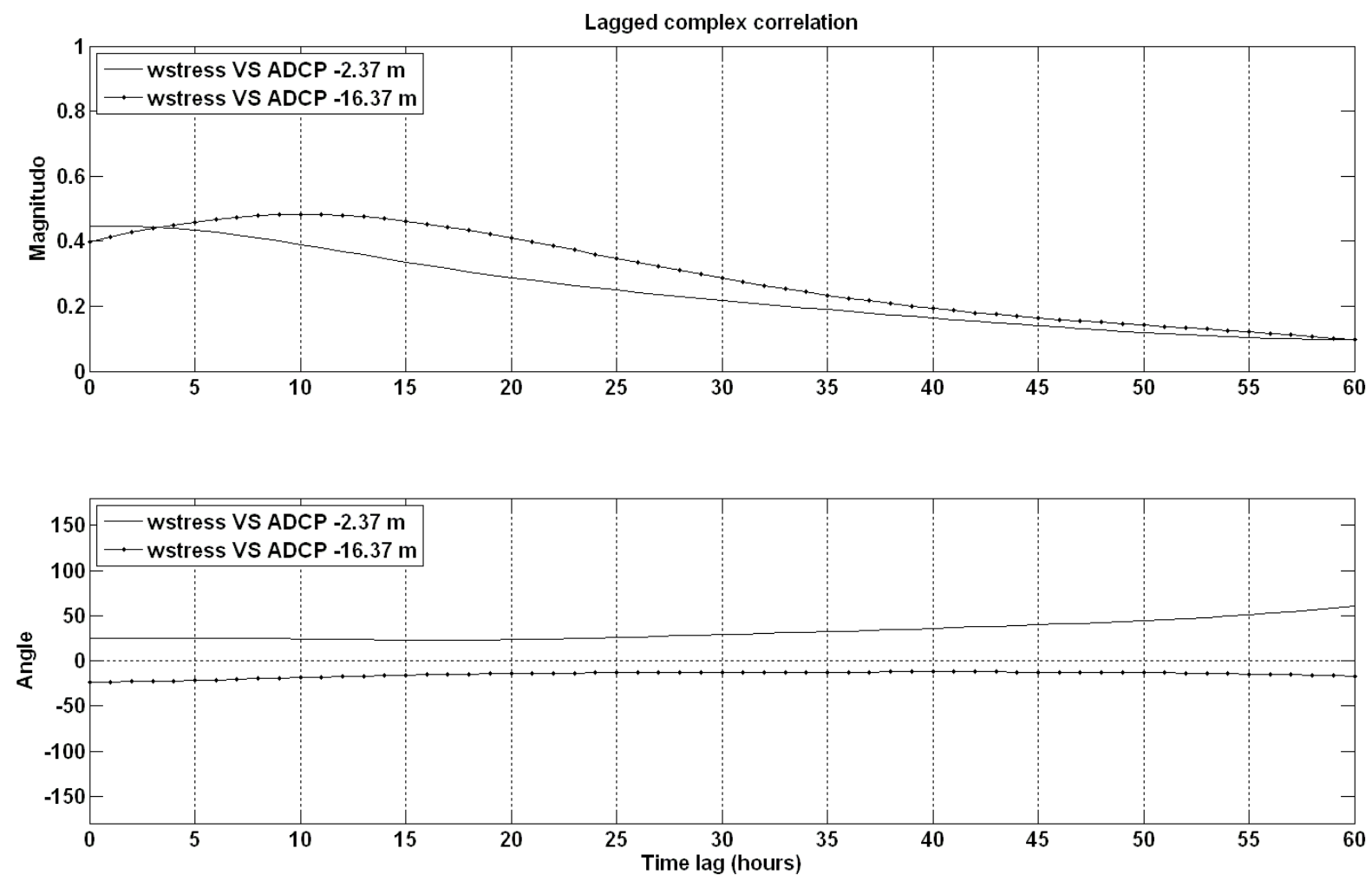

Fig. 12. Lagged complex (vector) cross-correlation between wind stress and low-passed ADCP subsurface currents. The solid line refers to the subsurface $(-2.37 \mathrm{~m})$ level, while the dash-dotted line refers to the bottom $(-16.37 \mathrm{~m})$ level. Veering angles for the same levels are depicted in the lower panel. Units are hours for the time lag on the x-axis, degrees for the y-axis in the veering angle plot.

A strong signal in the low frequency band (Msf constituent, periodicity 14 days) was also detected by the LSHA analysis, but the short duration of the record render ambiguous the significance of tidal analysis at this frequency. Moreover, no reference for the Adriatic Sea was found (apart that from Kovačević et al., 2004, for the surface current field in front of the Lagoon of Venice), that included this constituent in a tidal analysis. According to literature (Foreman, 1996), the time series length was adequate to include and resolve low frequency tidal constituents. On the other hand, Prandle (1987), in the analysis of surface current field from OSCR radar in the Northern Sea, interpreted forcing at this frequency as meteorologically driven rather than true astronomical contribution. These conclusions were also supported by estimates of the expected errors on ellipse amplitudes and phases as derived from the harmonic analysis (Godin, 1972). LSHA analysis of local wind stress vector for the investigated period (September-October 2002) potentially supported the interpretation of wind influence of the current field on both diurnal and low-frequency time scales. Most of the wind stress variance was in fact found in the Msf tidal frequency (major axis amplitude $0.5 \mathrm{~N} / \mathrm{m}^{2}$ ), and a weaker but significant contribution was also detected at the $\mathrm{K} 1$ tidal diurnal frequency (major axis amplitude $0.2 \mathrm{~N} / \mathrm{m}^{2}$ ).
No significant energy in wind stress time series was on the contrary detected at the semidiurnal time scale.

The cEOF analysis revealed the presence of two preferential modes of variability for the flow along the water column. Most of the variance of the currents was associated to EOF mode-1, describing the low-frequency circulation pattern or the motion associated with synoptic-scale meteorological disturbances, and extracted the barotropic (depthindependent) tidal forcing on a semidiurnal and diurnal frequencies. The remaining variance was explained by the baroclinic first EOF mode (mode-2), for which phase opposition between surface and bottom was obtained. This mode, containing energy in the anti-cyclonic spectrum in the frequency band spanning $17-30 \mathrm{~h}$, described the response of the water column to the high frequency, sea-breeze wind forcing.

The analysis of the time scales for the response of the water column to wind stress forcing evidenced the presence of two distinct layers having different currents-to-wind stress lag. The response was fast and immediate in the upper layer extending from surface to mid-depth, since no significant delay was obtained, in accordance with data analysis and numerical simulations. Numerical simulations of wind-driven circulation under bora wind regime (Orlić et al., 1994; Bergamasco and Gačić, 1996), evidenced that the sea response to 
wind action was in fact direct and prompt, with the lack of subtidal oscillations in the sea and a limited lag between wind and currents. The remaining portion of the water column was almost uniformly delayed by $11 \mathrm{~h}$, and with respect to the surface layer as well as the zero-lag correlation at bottom, the delay was statistically significant. The interpretation of the correlation analysis for the lower layer is straightforward if the effects of bottom friction to the motion along the water column, occurring on a typical time scale, are taken into account. When a rotating fluid is perturbed from its state of rest and the force responsible for the perturbation is not maintained, the flow adjusts to a geostrophic equilibrium in which pressure gradients are balanced by Coriolis accelerations. If, however, the flow extends to the bottom, frictional effects and the establishment of Ekman layers will remove energy from the flow. Under these conditions, the geostrophic equilibrium will not have permanent duration, and the fluid will "spin down" under bottom friction action (Gill, 1982). Based on the balance for depth-averaged along-shelf momentum in steady-state conditions under the assumption of negligible along-shelf pressure gradients, the frictional adjustment time scale (Whitney and Garvine, 2005) is proportional to local water depth, $H$, and inversely proportional to wind speed:

$T_{f}=\frac{H}{2 \sqrt{C_{D a \frac{\tau_{S x}}{\rho}}}}$

with $C_{D a}$ the drag-coefficient for depth-averaged currents in shallow waters and $\rho$ the density of sea water. Frictional adjustment occurs rather quickly in shallow waters: for an $8 \mathrm{~m} / \mathrm{s}$ wind speed, corresponding to $0.1 \mathrm{~N} / \mathrm{m}$ wind stress, adjustment takes place on a time scale $T_{f}$ of about $10 \mathrm{~h}$ in depths shallower than $30 \mathrm{~m}$ (Whitney and Garvine, 2005).

Estimates of the frictional adjustment time scale, $T_{f}$, for local wind stress for the investigated period, were computed following the proposed formulation for the average wind speed and corresponding wind stress magnitude $(4.8 \mathrm{~m} / \mathrm{s}$ and $0.047 \mathrm{~N} / \mathrm{m}^{2}$, respectively), as well as for wind speed larger than $5 \mathrm{~m} / \mathrm{s}$ and the corresponding wind stress value $(8 \mathrm{~m} / \mathrm{s}$ and $0.10 \mathrm{~N} / \mathrm{m}^{2}$ ). In the first case, the time scale for frictional adjustment was $8-9 \mathrm{~h}$ when, and reduced to $6 \mathrm{~h}$ when wind speed larger than $5 \mathrm{~m} / \mathrm{s}$ were considered. Adjustment time scales agree well with results of lagged cross-correlation analysis of current dependence on winds, and suggested the hypothesis of frictional dominated flow.

Acknowledgements. Subsurface ADCP data used in this work were kindly provided by J. Book of NRL and R. Signell of the NATO Undersea Research Centre in La Spezia. Data were collected as part of a Joint Research Programme between NRL and NATO Undersea Research Centre (NURC). J. Book provided also details on the ADCP data processing steps. Wind data at the oceanographic tower were available from the Municipality of Venice.

Topical Editor S. Gulev thanks I. Janekovic and another anonymous referee for their help in evaluating this paper.

\section{References}

Bergamasco, A. and Gačić, M.: Baroclinic response of the Adriatic Sea to an episode of bora wind, J. Phys. Oceanogr., 26, 13541369, 1996.

Bjornsson, H. and Venegas, S. A.: A manual for EOF and SVD analyses of climate data. McGill University, CCGCR Report 971, Montreal, Quebec, 52 p., 1997.

Book, J. W., Signell, R. P., and Perkins, H.: Measurements of storm and non-storm circulation in the northern Adriatic: October 2002-April 2003, J. Geophys. Res., 112, C11S92, doi:10.1029/2006JC003556.

Book, J. W., Perkins, H. T., Cavaleri, L., Doyle, J. D., and Pullen, J. D.: ADCP observations of the western Adriatic slope current during winter of 2001, Prog. Oceanogr., 66, 270-286, 2005.

Cosoli, S., Gačić, M., and Mazzoldi, A.: Comparison between HF radar current data and moored ADCP currentmeter, Nuovo Cimento, 25, C6, doi:10.1393/ncc/i2005-10032-6, 2005.

Cushman-Roisin, B., Gačić, M., Poulain, P. M., and Artegiani, A. (Eds.): Physical oceanography of the Adriatic Sea, Kluver Academic Publishers, Dordrecht, Boston London, 304 pp, 2001.

Davis, R. E.: Predictability of sea surface temperature and sea level pressure anomalies over the North Pacific Ocean, J. Phys. Oceanogr., 6(3), 249-266, 1976.

Dorman, C. E., Carniel, S., Cavaleri, L., Sclavo, M., Ghiggiato, J., Doyle, J., Haack, T., Pullen, J., Grbec, B., Vilibić, I., Janeković, I., Lee, C., Malačić, V., Orlić, M., Pachini, E., Russo, A., and Signell, R. P.: February 2003 marine atmospheric condition and the bora over the northern Adriatic, J. Geophys. Res., 111, C03S03, doi:10.1029/2005JC003134, 2006 (printed 112(C3), 2007).

Foreman, M. G. G.: Manual for tidal currents analysis and prediction. Pacific Marine Science Report, 78-6, Institute of Ocean Sciences, Patricia Bay, Sidney, British Columbia, Revised edition,, 1996.

Gill, A. E.: Atmosphere-Ocean Dynamics, International Geophysics Series, 30, Academic Press, 662 pp, 1982.

Godin G.: The analysis of tides, Liverpool University Press, 264 p., 1972.

Jenkins, G. M. and Watts, D. G.: Spectral analysis and its applications, Holden-Day Series in Time Series Analysis, Second Printing, 525 pp, 1969.

Kaihatu, J. M., Handler, R. A., Marmorino, G. O., and Shay, L. K.: Empirical orthogonal function analysis of ocean surface currents using complex and real-vector methods, J. Atmos. Ocean. Tech., 15, 927-941, 1998.

Kovačević, V., Gačić, M., Mancero Mosquera, I., Mazzoldi, A., and Marinetti, S.: HF radar observations in the Northern Adriatic: surface current field in front of the Venetian Lagoon, J. Marine Syst., 51, 95-122, 2004.

Kundu, P. K.: Ekman veering observed near the ocean bottom, J. Phys. Oceanogr., 6, 238-241, 1976.

Kuzmić, M., Janeković, I., Book, J. W., Martin, P. J., and Doyle, J. D.: Modeling the northern Adriatic double-gyre response to intense bora wind: A revisit, J. Geophys. Res., 111, C03S13, doi:10.1029/2005JC003377, 2006.

Large, W. G. and Pond, S.: Open ocean momentum flux measurements in moderate to strong winds, J. Phys. Oceanogr., 11, 324336, 1981.

Munchow, A. and Garvine, R. W.: Buoyancy and wind forcing of a 
coastal current, J. Mar. Res., 51, 293-322, 1993.

Munchow, A. and Chant, R. J.: Kinematics of inner shelf motion during the summer stratified season off New Jersey, J. Phys. Oceanogr., 30, 247-268, 2000.

North, G. R., Bell, T. L., Cahalan, R. F., and Moeng, F.: Sampling errors in the estimation of empirical orthogonal functions, Mon. Weather Rev., 110, 699-706, 1982.

Orlić, M., Kuzmić, M., and Pasarić, Z.: Response of the Adriatic Sea to the bora and sirocco forcing, Cont. Shelf Res., 14(1), 91116, 1994.

Pawlowicz, R., Beardsley, B., and Lentz, S.: Classical harmonic analysis including error estimates in MATLAB using T_TIDE, Comput. Geosci., 28, 929-937, 2002.
Prandle, D.: The fine-structure of nearshore tidal and residual circulations revealed by HF radar surface current measurements, J. Phys. Oceanogr., 17, 231-245, 1987.

Rosenfeld, L. K.: Diurnal period wind stress and current fluctuations over the continental shelf off Northern California, J. Geophys. Res., 93(C3), 2257-2276, 1988.

Venegas, S. A.: Statistical methods for signal detection in climate. Danish Center for Earth System Science, University of Copenhagen, DCESS Report 2, 2001.

Whitney, M. M. and Garvine, R. W.: Wind influence on a coastal buoyant outflow, J. Geophys. Res., 110, C030104, doi:10.1029/2003JC002261, 2005. 